\title{
Sediment patches, sediment supply, and channel morphology
}

\author{
W.E. Dietrich, P.A. Nelson, E. Yager, J.G. Venditti \& M.P. Lamb \\ Department of Earth and Planetary Science, University of California, Berkeley, Berkeley, CA, USA \\ L. Collins \\ Watershed Science, Berkeley, CA, USA
}

\begin{abstract}
Bed surface particle size patchiness may play a central role in bedload and morphologic response to changes in sediment supply in gravel-bed rivers. Here we test a 1-D model (from Parker ebook) of bedload transport, surface grain size, and channel profile with two previously published flume studies that documented bed surface response, and specifically patch development, to reduced sediment supply. The model over predicts slope changes and under predicts average bed surface grain size changes because it does not account for patch dynamics. Field studies reported here using painted rocks as tracers show that fine patches and coarse patches may initiate transport at the same stage, but that much greater transport occurs in the finer patches. A theory for patch development should include grain interactions (similar size grains stopping each other, fine ones mobilizing coarse particles), effects of boundary shear stress divergence, and sorting due to cross-stream sloping bed surfaces.
\end{abstract}

\section{INRODUCTION}

Most gravel-bed rivers, and many gravel-bedded flumes, display distinct patchiness in the surface sorting of particles. Figure 1 shows a detailed map of Wildcat Creek, near Berkeley, California, in which the organized heterogeneity of the bed surface is quantitatively displayed. This is a small $(\sim 7 \mathrm{~m}$ bankfull width), modestly steep (1.5\% slope) channel that receives a very high sediment load $(\sim 8000$ tonnes $/ \mathrm{km}^{2} / \mathrm{yr}$ in recent years; San Francisco Estuary Institute 2001). Much of the sediment is from deepseated landslides that periodically push massive amounts of debris ranging from boulders to clay into the channel. It is difficult to look at this map and not wonder how the river arranges unsorted debris into many distinct patches that range from boulder fields to sand patches. This map was made in 1987 following a period of particularly active landsliding and several years of high flows. Repeat visits to this reach since then have revealed two very different responses. In 1988, despite large amounts of bed surface mobilization, the distribution of patches remained relatively stable (except for where wood fell into the channel and redirected the flow). Yet over a longer time period, significant changes in the bed took place. Some of the high-flow coarse patches became buried with sand and subsequently vegetated. Occasional wood jams formed and caused local scour downstream and backwater-induced deposition upstream. Some of the boulders moved downstream. Now 17 years later, although the channel has changed, the assembly of patches, although distributed differently, by and large remains. This implies that some set of processes segregates a heterogeneous mixture of sediment into patches of distinct grain sizes. Some patches retain their location for decades while others come and go, but the range and number of classes persist. What leads to this patchiness, what sets the size distribution for a given patch, and how many patches should arise in a given reach of river? Presently there is limited theory and observation to guide an answer to these questions.

These questions address what we see so distinctly when walking along the channel, but they also raise other questions. All bedload transport models require a grain size distribution, be it of the surface or the subsurface (e.g. Parker \& Klingeman 1982, Parker 1990, Wilcock \& Crowe 2003). What grain size distribution should one use when there are distinct patches of sediment? One approach is to map the areal extent of each of the patch types and then determine an area-weighted grain size distribution. Some field methods guidelines specifically call for statistical procedures to sample through this variation to get a representative size distribution (see Bunte \& Abt (2001) for an excellent review of gravel-bed sampling methods). Although this procedure is straightforward, no local region of the bed surface consists of this size distribution, which makes it nearly useless. Instead, bedload transport rates and sizes vary locally due to the interaction of 


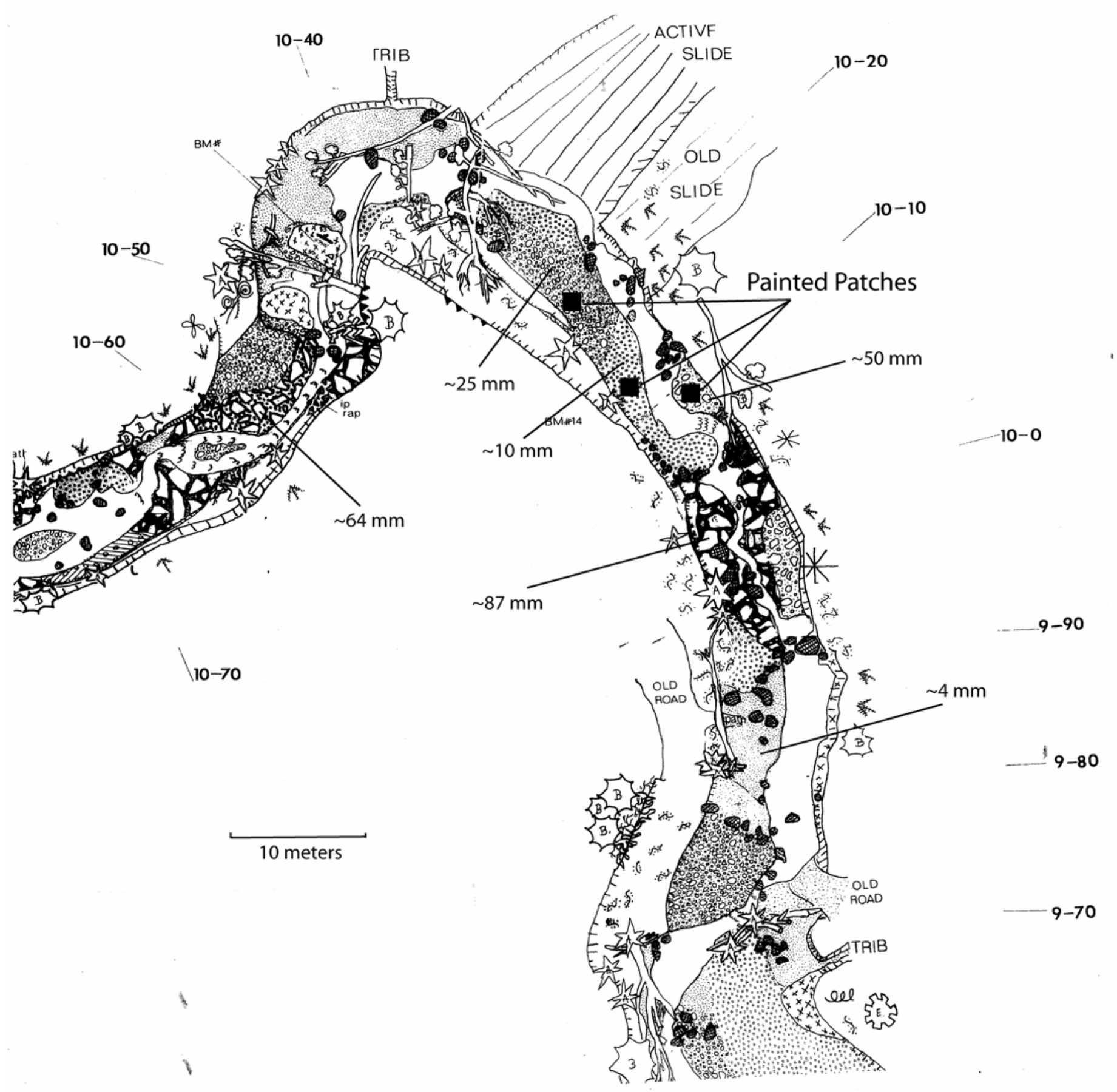

Figure 1. Facies map of Wildcat Creek, near Berkeley, CA, showing locations used in the painted rock study. Numbers along border are distances in meters. Tree locations along the bank are indicated by various symbols. Large woody debris is shown roughly to scale. Average median grain sizes are indicated for each facies type, and area with no pattern was covered by water. Flow is from left to right.

local flow fluctuations with the spatially heterogeneous bed surface texture. The sum of these fluxes across a channel yields the actual total bedload discharge.

Several studies of bedload transport and bed surface textures have suggested that the stagedependent size distribution of bedload in gravelbedded rivers may reflect the mobilization of progressively coarser patches with increasing discharge (e.g. Lisle \& Madej 1992, Lisle 1995, Garcia et al. 1999). The widely used bedload transport equation of Parker (1990) captures the observed stage- dependent mobility through a non-linear dependency of bedload flux on a hiding function and boundary shear stress. Some of this stage-dependent behavior may arise more from patch dynamics than from onedimensional grain size adjustments, as portrayed in the model. How well does the model perform when patchiness is an important part of the channel dynamics? The interaction between random fields of boundary shear stress and sediment patches will increase transport of fine material and selective transport of coarse sediment (Paola \& Seal 1995). Hence, it is not sufficient to simply characterize the size dis- 
tribution of the patches without estimating the appropriate shear stresses on the patches. In this regard, the coupled modeling and field study of Lisle et al. (2000) is particularly instructive. They found that the bankfull stage boundary shear stress field and the low-flow mapped grain size distribution were uncorrelated. Areas of finer sediment and local high boundary shear stress would then be expected to carry a disproportionate amount of the bedload because of the nonlinear flux dependency. Furthermore, a recent analytical model incorporating statistical variation in shear stress and bed patchiness (Ferguson 2003) suggests that cross-stream variance in hydraulic and critical shear stress for incipient motion can produce bedload fluxes substantially greater than those predicted in a one-dimensional, width-averaged calculation.

Experimental and field studies of gravel-bed channels have shown that the primary response to changes in sediment supply may be through the extent and size distribution of patches (Dietrich et al. 1989, Kinerson 1990, Lisle \& Madej 1992, Lisle et al. 1993, Lisle et al. 2000). Furthermore, in steep channels, boulders create a relatively immobile framework across which finer gravel passes. The boulders create large spatial deviations in flow that lead to local finer sediment deposition or scour. These streams are often supply-limited, which will strongly influence the extent of patch deposition. Successful prediction of bedload transport in such channels requires accounting for the area and size distribution of dynamic patches and the influence of boulders on the flow (Yager et al. 2004, 2005).

Here we examine the patch issue in three ways: 1) a model comparison between predicted and observed bed surface response to sediment supply, 2) a description of field observations on patch surface dynamics, and 3) a discussion of the controls on patch occurrence. The model and field studies highlight the importance of patch occurrence and dynamics.

\section{SURFACE RESPONSE TO REDUCED BEDLOAD SUPPLY: THE ROLE OF PATCHES}

In the late 1980's and early 1990's a series of papers were written based on experiments performed in the same flume in Japan that explored how a channel responds to reduced bedload supply (Dietrich et al. 1989, Iseya et al. 1989, Kirchner et al. 1990, Lisle et al. 1991, Lisle et al. 1993). The flume was straight, $0.3 \mathrm{~m}$ wide and $7.5 \mathrm{~m}$ long, and in all experiments it was given a constant water discharge, but a stepwise decrease in sediment feed rate. Details about the experimental observations and methods can be found in the published papers. The initial experi- ments (Dietrich et al. 1989, Kirchner et al. 1990) attempted to force a 1-dimensional response by running the flume at a low width-to-depth ratio $(\mathrm{w} / \mathrm{d} \approx$ 3). Although alternate bars did not form, at high feed rates well-defined, spatially-sorted bedload sheets (Whiting et al. 1988) developed and, with decreasing supply, lateral zones of coarser inactive bed emerged. With this decreasing sediment supply the area of active transport also narrowed and remained a relatively fine-textured surface.

Figure 2 shows the size distribution function of the feed, the initial bed surface (no sediment feed, and a short period of discharge sufficient to shift loose particles but cause no significant transport), and the bed surface at the high, medium and low feed rates. The feed and resulting bed surfaces were biomodal, which contributed to the strong development of bedload sheets and, as subsequently proposed by Paola \& Seal (1995), the overall patchiness of the bed surface. It is important to understand how the bed surface size distribution reported in Figure 2 (and previously in Dietrich et al. 1989) was generated. The bed surface tended to sort into three to four distinct patches ("congested" (coarse), "transitional", "smooth" (fine) and "inactive" (coarse zones during the lower feed rates) see Iseya \& Ikeda (1987) for discussion of terms). For each run, the entire bed surface was mapped into each of these categories (by eye) and then point counts were done on each patch. The size difference between the patches could be large. For example, for the highest feed case $(17.4 \mathrm{~g} / \mathrm{min}-\mathrm{cm})$ the median grain size of the smooth patch was $2.7 \mathrm{~mm}$, the transitional was 3.4 to $4.3 \mathrm{~mm}$ and the congested was $4.7 \mathrm{~mm}$. The congested areas tended to be more unimodal compared to the generally bimodal smooth and transitional areas. The single grain size distributions reported in Figure 2, however, are the area-weighted average grain size distributions of the entire bed.

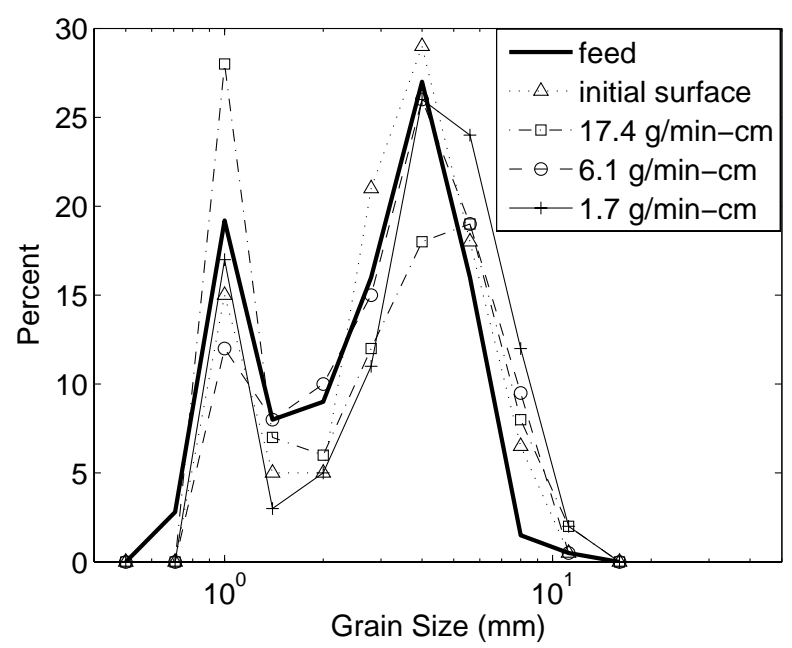

Figure 2. Grain size distributions of the feed and bed surface in the Dietrich et al. (1989) experiments. 
The median grain size of the spatially-averaged surface progressively increased with diminishing load from $3.7 \mathrm{~mm}$ (at $17.4 \mathrm{~g} / \mathrm{min}-\mathrm{cm}$ feed rate), to $4.3 \mathrm{~mm}$ (at $6.1 \mathrm{gm} / \mathrm{min}-\mathrm{cm}$ ), and then to $4.9 \mathrm{~mm}$ (at $1.7 \mathrm{gm} / \mathrm{min}-\mathrm{cm})$. This coarsening resulted from increased areas of congested and inactive patches. Except for the highest feed rate, the transitional bed surface predominated, leading to a modal value close to $4 \mathrm{~mm}$ (Fig. 2). Coarsening with reduced supply results from a great increase in the occurrence of the coarser fractions on the surface (Fig. 2).

Dietrich et al. (1989) suggested that the occurrence of the coarse surface layer in streams can be quantitatively linked to sediment supply. They reasoned that the primary response to a supply deficit is scour and hence surface coarsening, rather than channel degradation and slope reduction. The experiments suggest that this coarsening may be accomplished through expansion of coarse patches and narrowing of the finer-textured active bedload zone. They did note, however, that slope changed from 0.0052 (high feed rate) to 0.0046 (intermediate) and finally to 0.0035 (lowest). The water surface slope, bed surface slope, and bedload flux out of the flume reached approximate steady state in less than 1.5 hours, but considerable temporal fluctuations in these properties persisted throughout the experiments (e.g. 5 minute bedload transport samples gave approximately 5 to $33 \mathrm{~g} / \mathrm{min}-\mathrm{cm}$ for the $17.4 \mathrm{~g} / \mathrm{min}$ $\mathrm{cm}$ case, 0.7 to $12 \mathrm{~g} / \mathrm{min}-\mathrm{cm}$ for the $6.1 \mathrm{~g} / \mathrm{min}-\mathrm{cm}$ case and 0.3 to $7 \mathrm{gm} / \mathrm{min}-\mathrm{cm}$ for the $1.7 \mathrm{gm} / \mathrm{min}-\mathrm{cm}$ case). Some of this variation is due to inevitable small variations in feed rates and texture of the feed, which through grain interactions were sometimes amplified in the flume.

Lisle et al. (1993) used the same flume, but with a shallow flow such that the width-to-depth ratio was about 23. Stationary bars formed during their experiments. The grain size of the feed was nearly unimodal (Fig. 3), and finer than the narrow w/d case of Dietrich et al. (1989). Lisle et al. describe how coarse grain interactions controlled bar development, and, with decreasing sediment supply, the main flow incised, leaving the bars as inactive terraces. The bed surface was mapped into three distinct patch types based on percent gravel $(>50 \%, 5-$ $50 \%$, and $<5 \%$ ) and a single, area-weighted grain size distribution was reported. Feed rates decreased from $16.3 \mathrm{~g} / \mathrm{min}-\mathrm{cm}$, to $5.2 \mathrm{~g} / \mathrm{min}-\mathrm{cm}$, then to 1.6 $\mathrm{g} / \mathrm{min}-\mathrm{cm}$, which were comparable to the Dietrich et al. (1989) experiments. Median grain size systematically coarsened from $\sim 2.3 \mathrm{~mm}$ at the high feed rate, to $3.0 \mathrm{~mm}$ for the moderate and $3.8 \mathrm{~mm}$ for the lowest rate. The slope declined slightly from 0.031 to 0.028 . Lisle et al. emphasized that nearly all the adjustment to reduced load occurred through bed surface coarsening (as compared to slope change), in a manner consistent with the simple theory proposed by Dietrich et al. (1989). The bed surface initially coarsened through expansion of the intermediate size class (5-50\% gravel) and ultimately through expansion of the coarse size class. As in the small width-to-depth case, the zone of active transport narrowed considerably and was the area of finest bed surface. Additionally, there was considerable temporal variation in bedload flux throughout the experiment, with a tendency toward less fluctuation with time.

These two flume studies show that patch dynamics strongly influence the channel response to changes in sediment supply. There is some field support for these findings. Kinerson (1990) surveyed six channels with varying amounts of coarse sediment supply. He noted that the ratio of the median grain size of the surface relative to that of the subsurface was greater in channels with lower sediment supply, although patchiness caused large variations in this ratio. Following the proposal of Dietrich et al. (1989), he reasoned that the spatial extent of finer, unarmored patches may correlate with sediment supply.

Recently G. Parker has made available on his web page an ebook (G. Parker, 2005, 1D Sediment Transport Morphodynamics with Applications to Rivers and Turbidity Currents, hereinafter referred to as Parker ebook) and included in that ebook are useful Excel spreadsheets for performing morphodynamic calculations. One, entitled "RTebookAgDegNormGravMixPW.xls", is specifically set up to model the profile and grain size response of a river to altered bedload supply. The bedload equation used is either that of Parker (1990) or the recent Wilcock \& Crowe (2003) modification that specifically accounts for the presence of sand. Here we explore how well the model predicts the results in the Japan flume studies. This exploration reveals further the importance of patches.

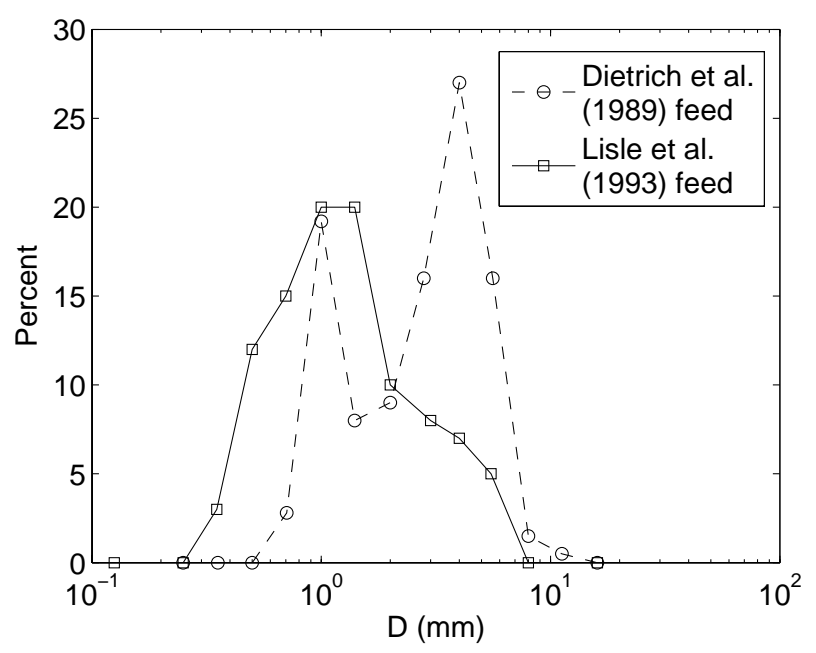

Figure 3. Grain size distributions of the Dietrich et al. (1989) and Lisle et al. (1993) experiments. 
The ebook model was used to simulate the small w/d experiments of Dietrich et al. (1989) and the large w/d experiments of Lisle et al. (1993). We modeled the initial high feed rate and then subsequent runs in which the feed rate was reduced. In each case the predicted surface grain size distribution (at the furthest upstream computational node) and average bed slope of the previous run were used as the initial conditions in the next run. Both experiments were modeled such that the model duration equaled the experiment duration. For each run in the small w/d case, the model approximately reached steady state (the median grain size varied down the flume by only about $10 \%$ and the sediment flux out of the downstream end was within $10 \%$ of the feed in (see Table 1)). The large w/d case, however, was far from steady state even at the end of each experimental run: the sediment flux out of the flume ranged from $35 \%$ to over $300 \%$ of the feed, depending on which stage of the experiment was being modeled (see Table 2). We therefore ran the model again until steady state conditions were met for each feed rate (typically orders of magnitude longer than the actual flume run durations). Table 3 provides the relevant input values used in each model run.

The results of the small $\mathrm{w} / \mathrm{d}$ flume experiments and model predictions are shown in Figures 2 and 4 and summarized in Table 1 . The model predicts a higher initial median grain size and less coarsening with decreasing feed rate than what was observed experimentally. The differences between predicted and observed grain sizes for the two reduced feed cases, however, are small, and perhaps within the range of error in flume measurement. The model predictions match the shape of the surface grain size distributions reasonably well (Fig. 4). The slope measured during the experiment's initially high sediment supply is matched by the model, but both reduced-feed rate slopes are predicted to be much less than those observed. The model also predicts a larger slope reduction than what was observed.
Table 1. Comparison of the Dietrich et al. (1989) flume observations with numerical model results. $\Delta$ denotes relative change, calculated as the change in the variable's magnitude between the two runs divided by the variable's magnitude in the earlier run, and qbT/qbTf is the ratio of the bedload transport rate at the downstream end of the flume to the sediment feed rate.

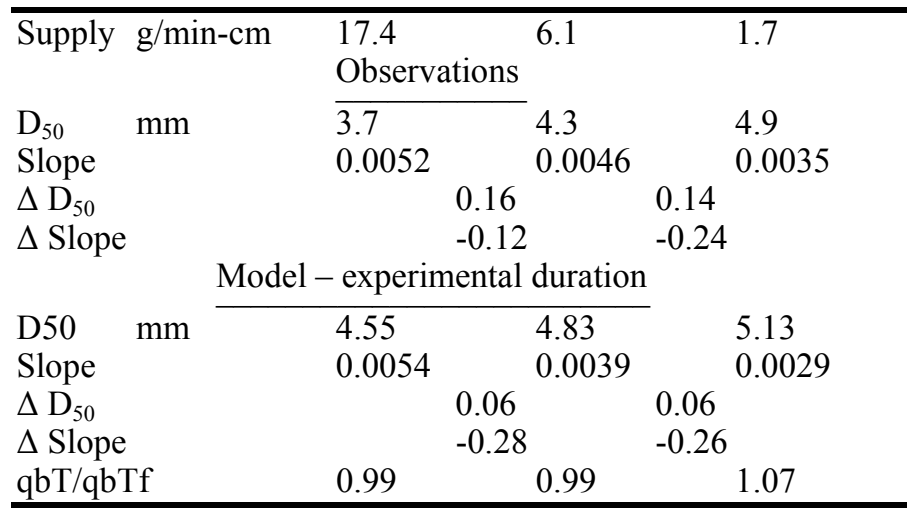

Table 2. Comparison of the Lisle et al. (1993) flume observations with numerical model results. Symbols and abbreviations are the same as in Table 1.

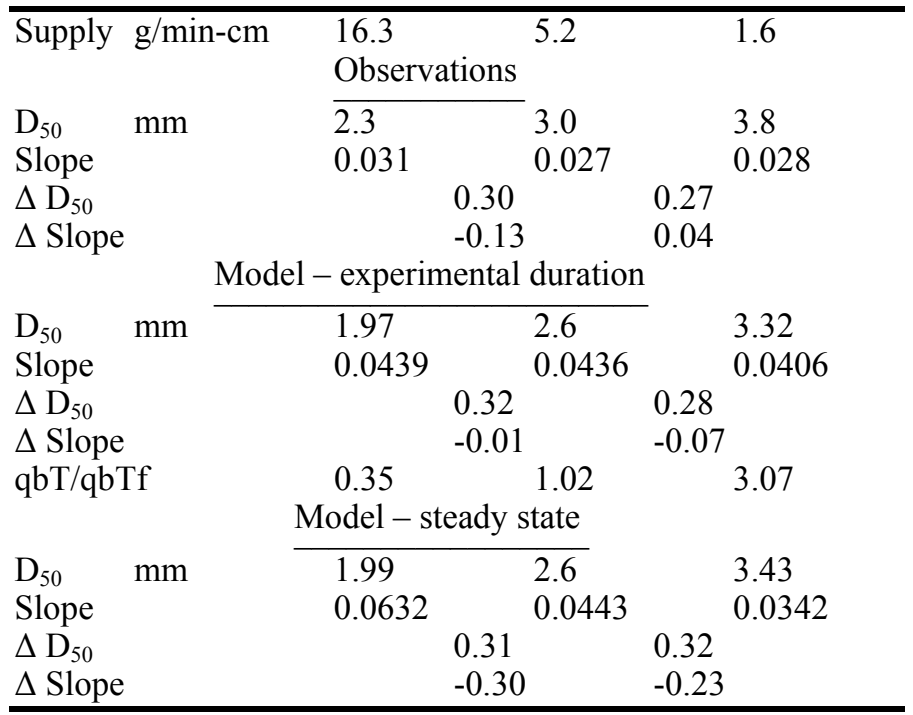

Table 3. Input parameters for numerical model runs. All runs were performed using the Wilcock \& Crowe (2003) bedload transport relation. Variables are defined as: qbTf: gravel input rate; qw: water discharge/width; I: intermittency; Sfbl: initial bed slope; L: reach length; dt: time step; $\mathrm{n}_{\mathrm{a}}$ : factor by which surface $\mathrm{D}_{90}$ is multiplied to obtain active layer thickness; Mtoprint: number of steps until a printout of results is made; Mprint: number of printouts after initial one. See Parker (ebook) for further details.

\begin{tabular}{|c|c|c|c|c|c|c|c|c|c|c|}
\hline \multirow{2}{*}{$\begin{array}{l}\text { Variable } \\
\text { gbTf }\end{array}$} & Units & \multicolumn{3}{|c|}{ Dietrich et al. } & \multicolumn{3}{|c|}{ Lisle et al. - experiment duration } & \multicolumn{3}{|c|}{ Lisle et al. - steady state } \\
\hline & $\mathrm{m}^{2} / \mathrm{s} \times 10^{-6}$ & 10.9 & 3.82 & 1.07 & 10.2 & 3.29 & 1.03 & 10.2 & 3.29 & 1.03 \\
\hline qw & $\mathrm{m}^{2} / \mathrm{s}$ & 0.06 & 0.06 & 0.06 & 0.00194 & 0.00194 & 0.00194 & 0.00194 & 0.00194 & 0.00194 \\
\hline $\mathrm{I}$ & & 1.0 & 1.0 & 1.0 & 1.0 & 1.0 & 1.0 & 1.0 & 1.0 & 1.0 \\
\hline Sfbl & & 0.0046 & 0.0054 & 0.0039 & 0.0310 & 0.0439 & 0.0436 & 0.0310 & 0.0632 & 0.0443 \\
\hline $\mathrm{L}$ & $\mathrm{m}$ & 7.5 & 7.5 & 7.5 & 7.5 & 7.5 & 7.5 & 7.5 & 7.5 & 7.5 \\
\hline $\mathrm{dt}$ & days $\times 10^{-5}$ & 2.6 & 2.5 & 1.4 & 1.0 & 1.0 & 1.0 & 1.0 & 1.0 & 1.0 \\
\hline $\mathrm{n}_{\mathrm{a}}$ & & 1 & 1 & 1 & 1 & 1 & 1 & 1 & 1 & 1 \\
\hline Mtoprint & & 2000 & 3000 & 3000 & 4167 & 3516 & 2735 & 40,000 & 100,000 & 50,000 \\
\hline Mprint & & 6 & 6 & 6 & 7 & 8 & 8 & 7 & 8 & 8 \\
\hline Calc time & $\mathrm{hr}$ & 7.5 & 10.8 & 6.0 & 7.0 & 6.75 & 5.25 & 67.2 & 192.0 & 96.0 \\
\hline
\end{tabular}



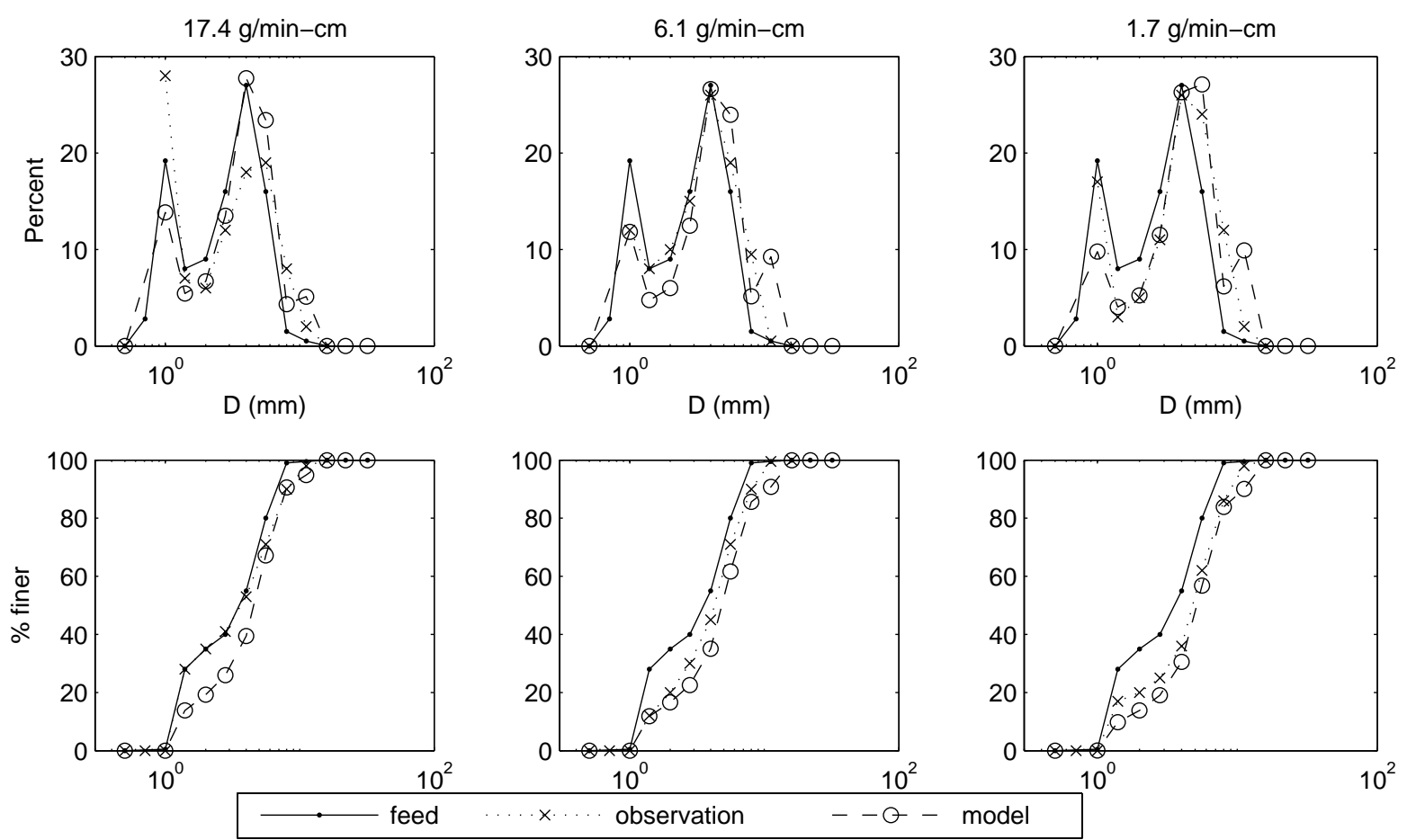

Figure 4. Probability (top) and cumulative (bottom) grain size distributions of the feed, the observed bed surface, and the bed surface predicted by the 1-D model, for the Dietrich et al. (1989) experiments.
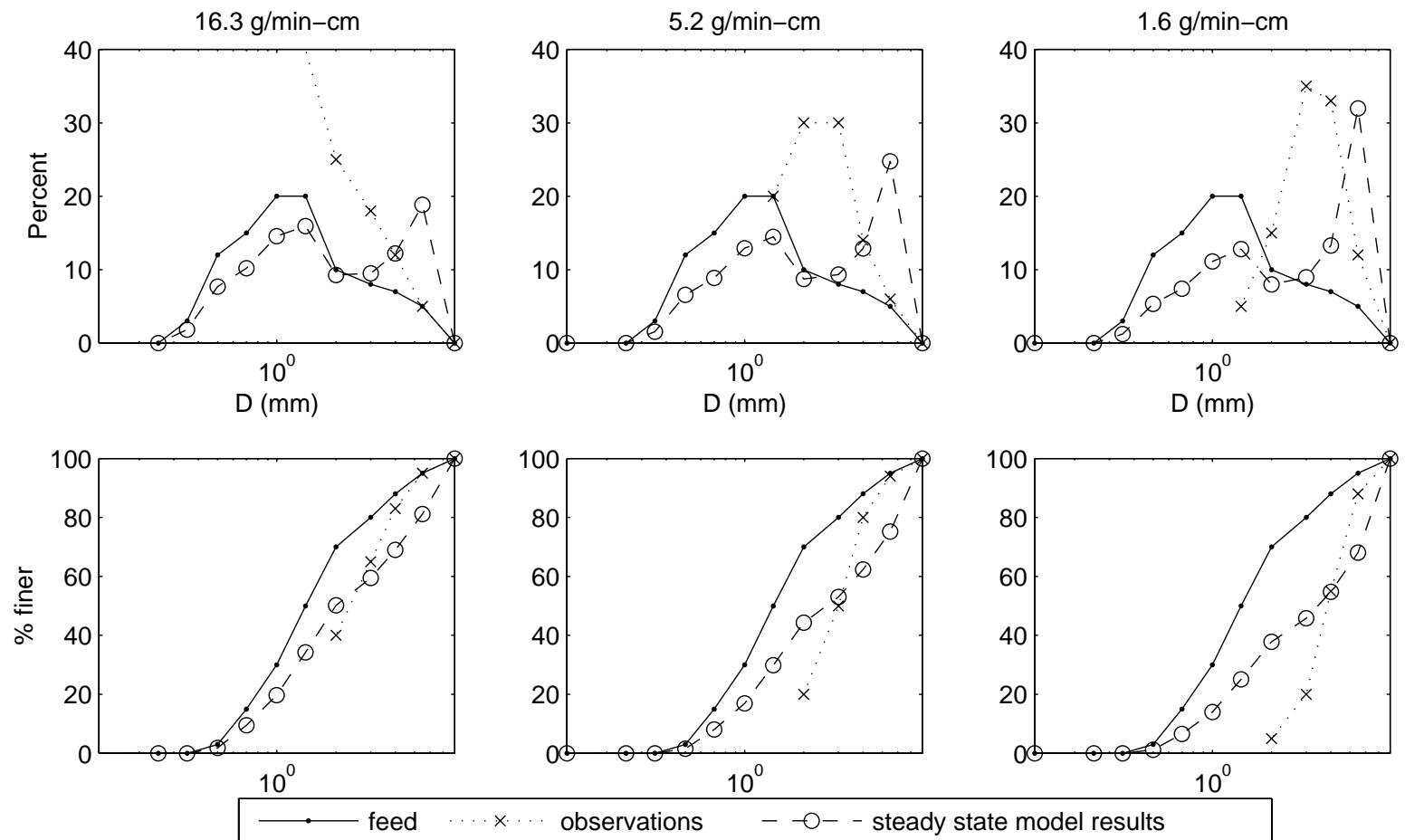

Figure 5. Probability (top) and cumulative (bottom) grain size distributions of the feed, the observed bed surface, and the steady state bed surface predicted by the 1-D model, for the Lisle et al. (1993) experiments.

For the Lisle et al. experiments (high w/d), Table 2 shows the values of slope and median grain size for the observed case, the numerical model run for the same duration as the experiments, and the steady state model results. Although the absolute values differ between the flume and model results for the experiment duration, the relative amount of change in slope and median grain size with decreased sediment supply is quite similar. In this case, however, the numerical model predicts that the flume would be far from steady state conditions. If the model is run to steady state, the median grain size differs little 
from the experimental observations, but the slope differs from them considerably. The initial slope is predicted to be 0.063 instead of the observed 0.031 and the final slope at the lowest feed rate is predicted to be 0.034 , compared to 0.028 . The numerical calculations, then, contrast with the Lisle et al. findings in that steady state took much longer to develop and the reduction in sediment feed led to the slope reducing to half its initial value, whereas only minor slope changes took place in the flume.

The surface distributions measured by Lisle et al. were unimodal; however, the steady state numerical model predicts a bimodal surface size distribution (Fig. 5). As a result, the median grain size of the surface is predicted rather well, but the model tends to over predict the relative amount of fine and coarse material and under predict the amount of intermediate material close to the median grain size. The Wilcock \& Crowe (2003) expression used in the Parker ebook model is based on an empirical fit to data from flume experiments in which the sediment size distributions were bimodal and trimodal (Wilcock et al. 2001). This may explain why the application of this expression to other experimental data may predict biomodality even when it does not occur.

In summary, for the small $\mathrm{w} / \mathrm{d}$ case the model is able to achieve steady state conditions on a timescale equivalent to that of the actual experiments, but for the large w/d case the model requires much more time to reach steady state than what was observed in the flume. In both cases, the model shows a tendency to over predict the slope change in response to a reduction in sediment supply. The model is fairly accurate in predicting changes in the median surface grain size, but it is far more successful at predicting the shape of the surface grain size distribution in the small w/d case than it is for the large $\mathrm{w} / \mathrm{d}$ case. It is unclear to what degree the model's relative success in predicting the surface grain size distribution depends on the use of a unimodal or bimodal feed or the presence or absence of twodimensional sediment transport dynamics. Lisle et al. also noted that bar development (something not treated explicitly in the Parker model) created additional drag and influenced the boundary shear stress available for sediment transport. Given that there was no calibration in application of the numerical model, overall it performed reasonably well in capturing the general magnitude of the response of grain size and slope change.

In light of this comparison, we propose that patch size adjustment in response to reduced sediment load caused the amount of scour and slope change to be less than what would otherwise occur; this effect was greatest in the high width-to-depth case. As both Dietrich et al. (1989) and Lisle et al. (1993) noted, the response to reduced load is the establishment of inactive coarse patches and a narrow zone of finer texture bedload transport. The development of this narrow zone may be the primary reason the experimental flumes reached steady state sooner than did the numerical model calculations, since the narrow zone allowed the adjusted bedload transport rate to propagate more quickly downstream.

The maps in Lisle et al. (1993) suggest that in the moderate to low feed cases, as sediment travels downstream it travels through successive fine and coarse patches. Hence, patches are exchanging sediment but remaining texturally distinct. We explore that possibility in field study in the following section.

\section{SEDIMENT DYNAMICS IN PATCHES: A FIELD STUDY}

The map in Figure 1 raises several questions about patch dynamics. As the stage rises, do the patches experience the onset of transport at the same discharge? It seems likely that fine patches would be more mobile than coarse ones, as Lisle \& Madej 1992) have suggested and Garcia et al. (1999) have inferred. If so, does sediment released from the fine patch cross into the coarser patches and influence the mobility of particles there? Given that finer patches are of finite extent, do they tend to scour and disappear if modest flow events persist? Here we describe some simple observations based on painted rock measurements for Wildcat Creek, CA (the site in Figure 1).

We painted $1 \mathrm{~m}^{2}$ areas in three patches (Fig. 1) at the end of the dry season of 1987 . We also painted large numbers on the boulder field at the downstream end of the site. This was done following a stormy previous year in which large quantities of sediment had entered the channel via deep-seated landsliding. Each of the painted patches had moved in the previous season. Each patch was point counted to determine its size distribution. Over the next two wet seasons these patches were recounted two to seven times (Fig. 6). These two years were relatively dry, with peak flow reaching only 0.37 and 0.93 of the 1.5-year recurrent discharge of about $5.7 \mathrm{~m}^{3} / \mathrm{s}$. In the first year, movement took place in the two finer patches, but not in the coarsest, and no significant change took place in the patch grain size distributions. The two finer patches were then repainted in the fall of 1988 and subsequent point counts kept track of both the painted and unpainted particles in the patch. All the painted particles were transported from the finest patch (Sta. $1010 \mathrm{~m}$ ) during the first significant runoff event. Subsequent point counts show that the patch coarsened and then fined some relative to the initial values, but generally maintained the same size distribution. Grain size counting was done as much as possible by measur- 
ing the particles in place, rather than by picking them up, in order to minimize disturbance from measurement.

The intermediate patch (Sta. $1018 \mathrm{~m}$ ) progressively lost painted particles through the winter runoff. The unpainted rocks observed in this patch were both exposed rocks from the bed below and replacement rocks from upstream. These unpainted rocks had fewer large rocks than the original bed and the size distribution of the remaining unpainted rocks was generally unchanged. Overall, the patch lost most of its original particles but changed little in grain size.

The coarsest patch (Sta. $1008.3 \mathrm{~m}$ ) experienced no transport. This patch lay at a somewhat higher location along the channel bank and in the spring of 1989, a high flow brought sand onto the patch, burying much of it. This led to the patch being colonized by vegetation, and it has remained buried since then.

These observations demonstrate that patch dynamics are size-dependent, with finer patches experiencing frequent movement and coarser ones less so. Patch size distribution can remain about the same despite complete replacement of all particles, and patches can persist in the same location for several years despite transmitting large quantities of sediment.

We painted two patches at a second site $5 \mathrm{~km}$ upstream (Fig. 7) where the channel is narrower. In this reach the patches span the width of the bed and are locally arranged in series due to sequential downstream changes in width and slope. We painted one fine patch of sand and gravel and a downstream patch of sand, gravel and cobble (Fig. 8). As we found at the downstream site (Fig. 1), the finer patch (Sta. $6145.6 \mathrm{~m}$ ) experienced complete replacement with the first flow event but remained texturally the same. The downstream displacement of these particles was traced. Most of the particles released during the first runoff event from the upstream fine patch crossed the painted coarser patch downstream, although some of the finer particles came to rest in this coarser patch. In contrast, the coarser patch (Sta. $6131.7 \mathrm{~m}$ ) progressively lost painted rocks, with finer painted particles experiencing net loss first (note the range of sizes reported in the plots). The unpainted rocks were finer at first, but then coarsened, eventually exceeding the range of the original surface. All sizes in the coarse patch moved, and similar sizes arrived from upstream having crossed the fine patch located upstream. These observations indicate that the alternative fine-coarse sequence remained stable while actively exchanging with all size ranges passing downstream. Fine particles crossed the coarse patch without fining it and coarse particles crossed the fine patch without coarsening it.

\section{DISCUSSION}

Flume and field studies reported and cited above show that grain size surface patches are common, and multiple patch sizes will develop even in unimodal sediment. Observations in straight flumes suggest that patch development affects bed surface dynamics and favors the topographic shoaling or emergence of coarse-textured patches. Experiments in which sediment supply is reduced favor the stagnation and emergence of these coarse patches and the concentration of finer bedload transport into the fine patches. Field studies suggest that patchiness may be correlated with sediment supply (Kinerson 1990). Tracer studies reported here show that coarse and fine particles may begin transport at similar stages, but that finer patches are significantly more mobile. This supports results from other field studies (e.g. Lisle \& Madej 1992, Garcia et al. 1999). The tracer studies also show that the patches exchange particles with the through going bedload, yet can remain unchanged. Particles from fine patches cross coarse patches and vice versa. The finer patches are fully mobile while the coarse patches probably vary from partial to selective transport with increasing local boundary shear stress.

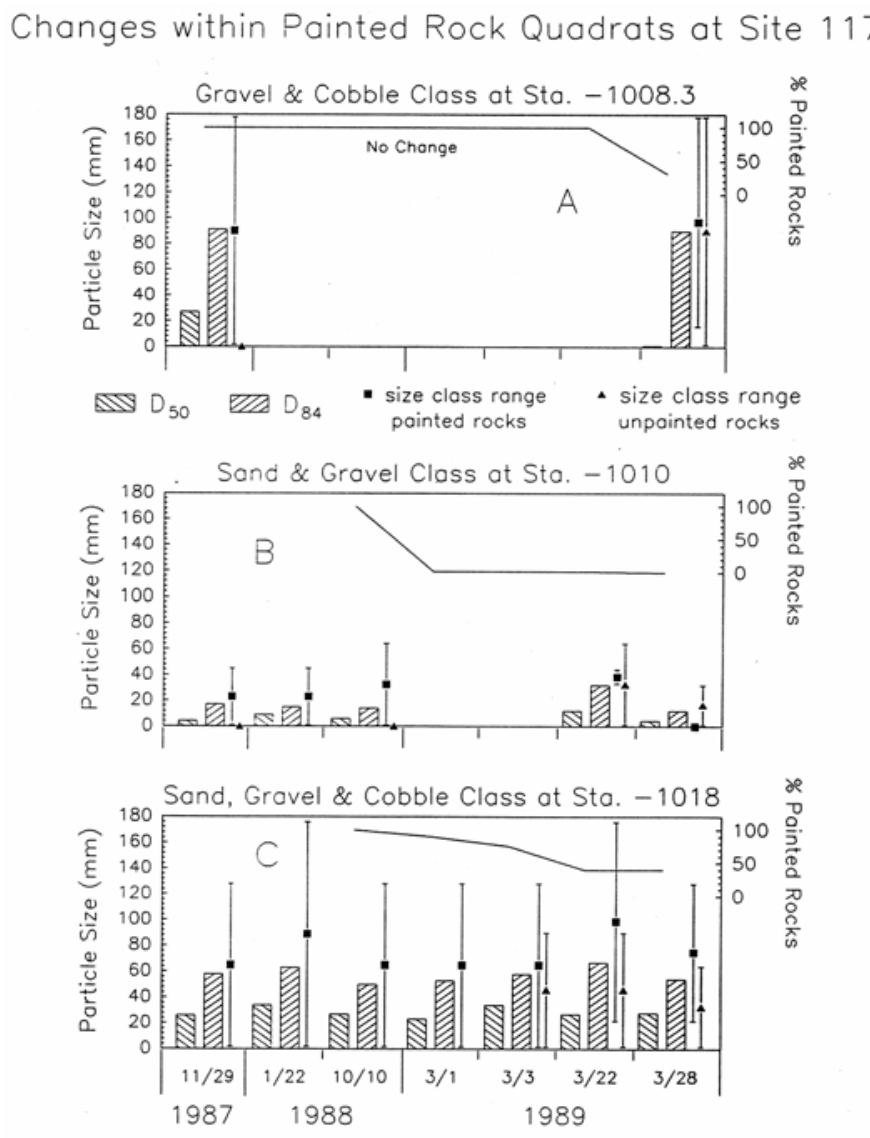

Figure 6. Data from the painted rock study performed at the three patches illustrated in Figure 1. Station numbers increase in the upstream direction, and are shown along the border of the channel in Figure 1 (e.g. 10-10=1010 m). 


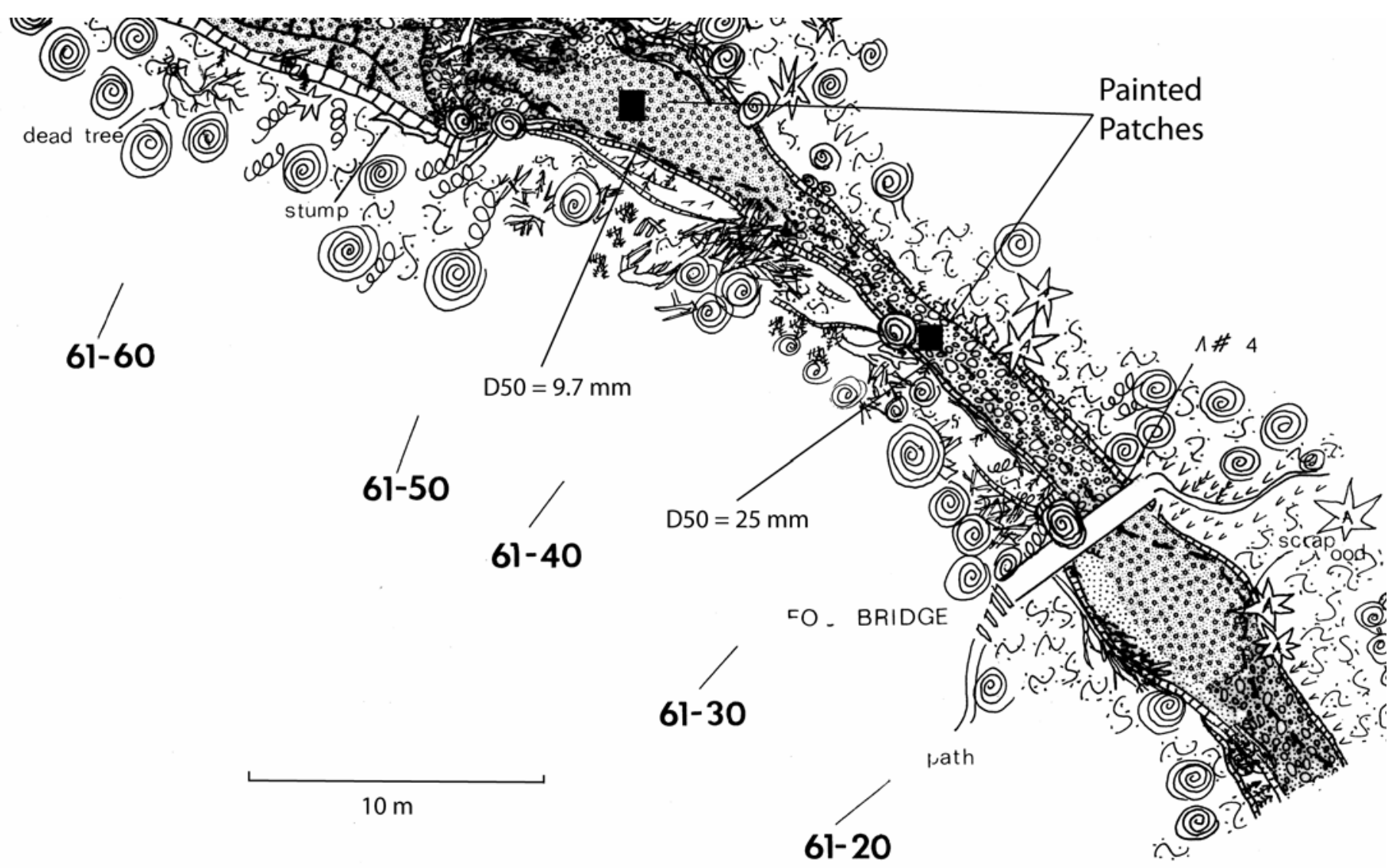

Figure 7. Facies map of the upstream site of Wildcat Creek where painted rock studies were performed. Symbols for bed texture are the same as in Figure 1. Spiral forms along banks are the location of trees. A footbridge crosses the channel near 61-20. Flow is from left to right.

Changes within Painted Rock Quadrats at Dam Site
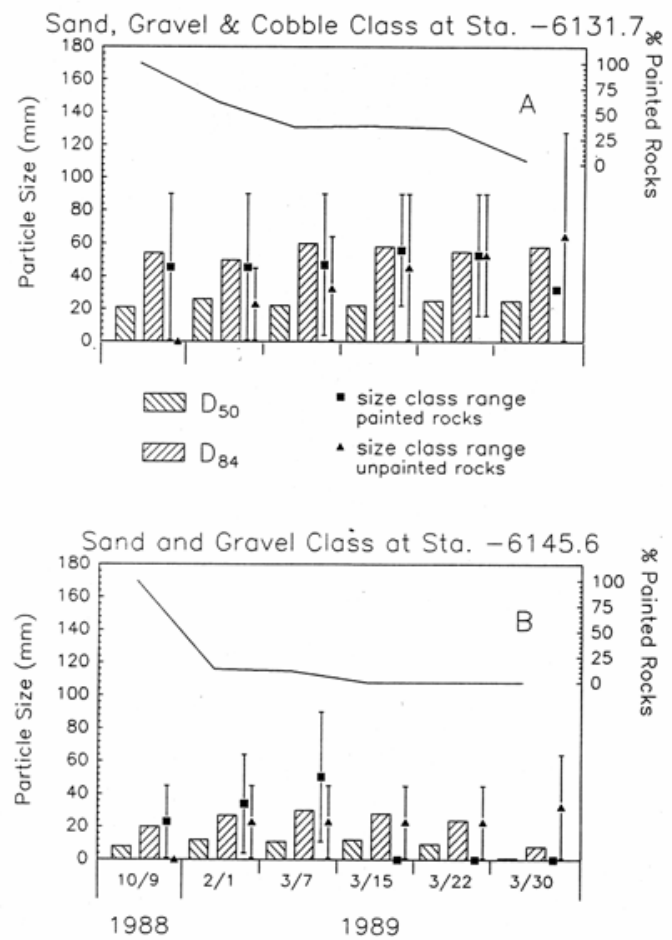

Figure 8. Data from the painted rock study performed at the two patches illustrated in Figure 7. Station numbers increase in the upstream direction, and are shown in Figure 7.
Spatial structure to bed surface sorting is typically strongly developed in river meanders with bed surfaces coarsening from the outside to the inside bank on the upstream end of the bed, and fining inward on the downstream end of the bend (e.g. Dietrich \& Smith 1984, Bridge 1992, Hoey \& Bluck 1999). In sand-bedded meandering rivers, the bed surface can be fully mobile, and yet this spatial structure of the grain sorting is temporally constant. Dietrich \& Smith (1984) concluded that topographically-induced stress divergences, which would tend to create scour or deposition (depending on sign), were balanced by cross-stream fluxes of sediment. Across the point bar slope into the pool, particles roll outward against inward secondary circulation, causing large particles to roll into zones of high boundary shear stress and fine particles to be carried into zones of low boundary shear stress. Sandbedded rivers are typically not described as having a patchy bed because the grain sorting tends to be more continuous, but the grain size across the channel can vary by a factor of 6 (Dietrich \& Smith 1984). In gravel-bedded rivers, topographicallyinduced boundary shear stress divergences may be primarily compensated by grain size adjustments, and the bedload transport field may be uncorrelated with the boundary shear stress field (Dietrich \& Whiting 1989, Lisle et al. 2000). We could not find any field studies of bedload transport through mean- 
dering gravel-bedded rivers that document controls on grain size adjustments.

These studies suggest that there should be three components of a complete patch theory: grain interactions, stress-divergence response, and lateral sorting effects. Whiting et al. (1988) and Dietrich et al. (1989) argued that a "catch and mobilize" process gives rise to mobile, downstream spatially-sorted bedload sheets. Seminara et al. (1996) used a stability analysis to show that the formation of bedload sheets may be highly dependent upon the deviation from equal mobility of different grain sizes in the surface layer, and that their growth is strictly associated with grain sorting. In a heterogeneous mixture of sediment, coarse particles will tend to "catch" other coarse particles in their wake and cause them to stop moving. Fine particles also trapped by the coarse particles will mobilize the coarse particles, perhaps through smoothing or altering the exposure or friction angle of the coarse particles. Once mobile, the coarse particles will run across the smoothed areas until stopped again by other coarse particles. The Wilcock \& Crowe (2003) bedload transport model explicitly includes sand mobilization of coarse particles. As Paola \& Seal (1995) reasoned, for a given mixture of sediment there must be some upper size class that will not be mobilized by the finer fraction and also there should be some lower size class that either goes into suspension or is too small and numerous to be slowed by the wakes of the coarser particles. These observations suggest that patchiness is an intrinsic tendency in sufficiently heterogeneous sediment. Although patchy bed surfaces form under steady uniform flow in straight narrow channels, unsteady hydrographs, which can cause transient preferential movement of patches, probably strongly reinforce patchiness (e.g. Lisle \& Madej 1992, Parker et al. 2003).

The response to local boundary shear stress divergence in channels actively transporting sediment is through some combination of grain size adjustment, topographic adjustment, and cross-stream compensating sediment transport. It is not clear if current models would predict a purely grain size response. The Parker ebook discussion on armoring nicely illustrates how both slope and bed surface grain size are expected to covary for a constant bedload size distribution in response to varying sediment supply. Comparison with flume experiments here illustrates that the model tends to favor topographic change rather than grain size adjustment. It may be that the empirical structure of the underlying nonlinear dependency of bedload flux on the hiding function term does not permit a predominantly grain size response. Furthermore, the use of the WilcockCrowe bedload function predicts bed surface bimodality where sand is present. This was not consistent with the Lisle et al. observations. The empirical na- ture of the Wilcock-Crowe expression makes its application to sorting problems less certain.

Lateral sorting effects arise when there is crossstream topography, where a cross-stream slope and commonly associated secondary currents create an ideal condition for grain sorting as described above. Well-developed theory exists for this process (Sekine \& Parker 1992, Kovacs \& Parker 1994). For channels with well-developed bars and pools or scour holes and lobate deposits, inclusion of this lateral sorting effect may be of first-order importance.

\section{CONCLUSIONS}

Patch dynamics appears to be a primary response to altered sediment supply. The Parker ebook spreadsheet comparison with the two flume studies shows that the model can predict the median grain size reasonably well, but it may incorrectly predict the surface grain size distribution and it tends to greatly over predict the steady state channel slope at low feed rates. The model also predicts a much longer time to steady state than observed in the flume. Lateral coarsening and narrowing of the finer textured zone of active bedload transport leads to less topographic change and more rapid response to altered sediment supply than predicted from the model. Application of the Wilcock \& Crowe (2003) bedload expression in the Parker model consistently predicts a bimodal bed surface size distribution, even when the sediment source is unimodal. The unimodal sediment feed can nonetheless lead to strong patch development, especially in high width-to-depth channels in which bars emerge, interact with the flow, and strongly influence particle sorting.

Field studies using painted rocks illustrate that particles from different size patches must cross each other, even while the individual size distribution of the patches remains roughly constant. Grain interactions, transport and grain size adjustment associated with boundary shear stress divergence fields, and sorting processes on cross-channel slopes need to be coupled for a complete patch theory.

\section{ACKNOWLDEGEMENTS}

This work was supported in part by the California Water Resources Center and the NSF National Center for Earth Surface Dynamics.

\section{REFERENCES}

Bridge, J.S. 1992. A revised model for water flow, sediment transport, bed topography, and grain size sorting in natural river bends. Water Resources Research 28(4): 999-1013. 
Bunte, K. \& Abt, S.R. 2001. Sampling surface and subsurface particle-size distributions in wadable gravel- and cobblebed streams for analyses in sediment transport, hydraulics and streambed monitoring, US Forest Service, General Techn. Report RMRS-GTR-74, 450 pp.

Dietrich, W.E., Kirchner, J.W., Ikeda, H., \& Iseya, F. 1989. Sediment supply and the development of the coarse surface layer in gravel-bedded rivers. Nature 340: 215-217.

Dietrich, W.E. \& Smith, J.D. 1984. Bed load transport in a river meander. Water Resources Research 20: 1355-1380.

Dietrich, W.E. \& Whiting, P.J. 1989. Boundary shear stress and sediment transport in river meanders of sand and gravel. In S. Ikeda \& G. Parker (eds), River Meandering, American Geophysical Union Water Resources Monograph 12. Washington D.C.: American Geophysical Union.

Ferguson, R.I. 2003. The missing dimension: effects of lateral variation on 1-D calculations of fluvial bedload transport. Geomorphology 56: 1-14.

Garcia, C., Laronne, J.B., \& Sala, M. 1999. Variable source areas of bedload in a gravel-bed stream. Journal of Sedimentary Research 69(1): 27-31.

Hoey, T.B. \& Bluck, B.J. 1999. Identifying the controls over downstream fining of river gravels. Journal of Sedimentary Research 69(1): 40-50.

Iseya, F. \& Ikeda, H. 1987. Pulsations in bedload transport rates induced by a longitudinal sediment sorting: a flume study using sand and gravel mixtures, Geografiska Annaller 69(1): 15-27.

Iseya, F., Ikeda H., \& Lisle, T.E. 1989. Fill-top and fill-strath terraces in a flume with decreasing sediment supply of sand-gravel mixtures. Transactions Japanese Geomorphological Union 10(4): 323-342.

Kinerson, D. 1990. Surface response to sediment supply, M.S. thesis, Univ. of Calif., Berkeley.

Kirchner, J.W., Dietrich, W.E., Iseya, F. \& Ikeda, H. 1990. The variability of critical shear stress, friction angle, and grain protrusion in water-worked sediments. Sedimentology 37: 647-672.

Kovacs, A. \& Parker, G. 1994. A new vectorial bedload formulation and its application to the time evolution of straight rivers. Journal of Fluid Mechanics 267: 153-183.

Lisle, T.E., Ikeda, H., \& Iseya, F. 1991. Formation of stationary alternate bars in a steep channel with mixed-size sediment: a flume experiment. Earth Surface Processes and Landforms 16(5): 463-469.

Lisle, T.E. Iseya, F. \& Ikeda, H. 1993. Response of a channel with alternate bars to a decrease in supply of mixed-size bed load: a flume experiment. Water Resources Research 29(11): 3623-3629.

Lisle, T.E. \& Madej, M.A. 1992. Spatial variation in armouring in a channel with high sediment supply. In P. Billi, R.D. Hey, C.R. Thorne, \& P. Tacconi (eds), Dynamics of Gravel-Bed Rivers. New York: John Wiley.

Lisle, T.E., Nelson, J.M., Pitlick, J., Madej, M.A., \& Barkett, B.L. 2000. Variability of bed mobility in natural, gravel- bed channels and adjustments to sediment load at local and reach scales. Water Resources Research 36(12): 37433755 .

Paola, C. \& Seal, R. 1995. Grain size patchiness as a cause of selective deposition and downstream fining. Water Resources Research 31(5): 1395-1407.

Parker, G. \& Klingeman, P.C. 1982. On why gravel bed streams are paved. Water Resources Research 18(5): 14091423.

Parker, G. 1990. Surface-based bedload transport relation for gravel rivers. Journal of Hydraulic Research 28(4): 417436.

Parker, G., Toro-Escobar, C.M., Ramey, M. \& Beck, S. 2003. Effect of floodwater extraction on mountain stream morphology. Journal of Hydraulic Engineering. 125(11): 885895.

San Francisco Estuary Institute. 2001. Wildcat Creek: a scientific study of physical processes and land use effects, report, $85 \mathrm{pp}$.

Sekine, M \& Parker, G. 1992. Bedload transport on transverse slopes. Journal of Hydraulic Engineering 118(4): 513-535.

Seminara, G., Colombini, M., \& Parker, G. 1996. Nearly pure sorting waves and formation of bedload sheets. Journal of Fluid Mechanics 312: 253-278.

Whiting, P.J., Dietrich, W.E., Leopold, L.B., Drake, T.G., \& Shreve, R.L. 1988. Bedload sheets in heterogeneous sediment. Geology 16: 105-108.

Wilcock, P.R. \& Crowe, J.C. 2003. A surface-based transport model for sand and gravel. Journal of Hydraulic Engineering 29: 120-128.

Wilcock, P.R., Kenworthy, S.T., \& Crowe, J.C. 2001. Experimental study of the transport of mixed sand and gravel. Water Resources Research 37(12): 3349-3358.

Yager, E., McCardell, B.W., Dietrich, W.E., \& Kirchner, J.W. 2005. Measurements of flow and transport in a steep, rough stream. Geophysical Research Abstracts 7(05836).

Yager, E., Schmeekle, M., Dietrich, W.E., \& Kirchner, J.W. 2004. The effect of large roughness elements on local flow and bedload transport. Eos Transactions AGU 85(47), Fall Meeting Supplement, Abstract H41G-05. 